\title{
REVIEW
}

\section{The mucosal immune system in the oral cavity-an orchestra of T cell diversity}

\author{
Rui-Qing Wu ${ }^{1,2}$, Dun-Fang Zhang ${ }^{1,2}$, Eric Tu ${ }^{1}$, Qian-Ming Chen ${ }^{2}$ and WanJun Chen ${ }^{1}$
}

The mucosal immune system defends against a vast array of pathogens, yet it exhibits limited responses to commensal microorganisms under healthy conditions. The oral-pharyngeal cavity, the gateway for both the gastrointestinal and respiratory tracts, is composed of complex anatomical structures and is constantly challenged by antigens from air and food. The mucosal immune system of the oral-pharyngeal cavity must prevent pathogen entry while maintaining immune homeostasis, which is achieved via a range of mechanisms that are similar or different to those utilized by the gastrointestinal immune system. In this review, we summarize the features of the mucosal immune system, focusing on T cell subsets and their functions. We also discuss our current understanding of the oral-pharyngeal mucosal immune system. International Journal of Oral Science (2014) 6, 125-132; doi:10.1038/ijos.2014.48; published 8 August 2014

Keywords: mucosal immune system; oral-pharyngeal mucosa; T cell

\section{INTRODUCTION}

The oral-pharyngeal cavity is composed of sophisticated anatomical structures. Various microorganisms colonize the environment provided by those structures. In addition to microbes, food particles and external substances consumed through the oral cavity present potential challenges to the homeostasis of the oral mucosa. Hence, a mucosal membrane and inherent mucosal immune system are indispensable for the protection of the integrity of the internal environment. The mucosal immune system mounts immune responses through immune cells residing in mucosal compartments. T lymphocytes residing in the mucosa play important roles in mucosal immunity and tolerance. In addition, $\mathrm{T}$ cell deficiency or defects in $\mathrm{T}$ cell function are associated with several oral mucosal diseases. However, the phenotype and function of $\mathrm{T}$ cell subsets that reside in the oral mucosa remain largely undetermined. Thus, it is crucial to understand the diversity and functions of mucosal $\mathrm{T}$ cell subsets in healthy and pathological conditions.

\section{THE MUCOSAL IMMUNE SYSTEM}

The mucosal immune system is a localized and specific immune organization protecting nearly the whole inner surface of the human body, spanning the mucosal surfaces of the oral-pharyngeal cavity, gastrointestinal (GI) tract, respiratory tract and urogenital tract, as well as the exocrine glands. ${ }^{1}$ Despite differences in their locations, the mucosal immune system at different organs share similar anatomical organization and features. As the GI mucosal immune system is better understood, we will discuss here the features of the mucosal immune system based on our knowledge of the GI immune system. The GI mucosal immune system is composed of three major compartments: the epithelial layer, lamina propria (LP) and the mucosal-associated lymphoid tissue (MALT), which, in the GI tract, is referred to as gut-associated lymphoid tissue. The gut-associated lymphoid tissue consists of Peyer's patches and isolated lymphoid follicles. The epithelium and LP are the battlefront, and the MALTs represent the headquarters where adaptive immune responses are initiated (Figure 1). T cells are abundant in the GI immune system. In normal mice, there is approximately one intraepithelial lymphocyte (IEL) per 5-10 epithelial cells (ECs) in the small intestine; in the colon, this ratio is approximately one IEL per $40 \mathrm{ECs}^{2}$ In healthy adults, it is estimated that one IEL exists per 5-20 ECs in the intestines. ${ }^{3}$ Nonetheless, the ratios and compositions of IELs may vary depending on the condition of the host. Antigen presenting cells (APCs) capture antigens from the epithelium and microfold cells (Mcells) in Peyer's patches and then migrate to lymphoid follicles, LP and mesenteric lymph nodes, where $\mathrm{T}$ cells are exposed to antigens presented by APCs. After antigen recognition, these $\mathrm{T}$ cells become activated and differentiate into effector cells (Figure 1). ${ }^{1-2}$ Lymphocytes, including IELs and LP lymphocytes, form a network that ensures the integrity of the mucosal barrier and GI environment.

Conventional $\mathrm{T}$ cells in the mucosa can be classified as either major histocompatibility class II (MHC II)-restricted and $\alpha \beta$ T cell receptor (TCR)-expressing CD4 ${ }^{+}$T cells (helper T cells, or $\mathrm{T}_{\mathrm{H}}$ cells) or MHC I-restricted and $\alpha \beta$ TCR-expressing $\alpha \beta^{+}$T cells. These T cells develop in the thymus and migrate into mucosal effecting sites after encountering antigen stimuli in lymphoid tissues. ${ }^{2,4}$ However, in the mucosa, another unique subset of T cells exists within the epithelial layer. These T cells express either $\alpha \beta$ or $\gamma \delta$ TCR and mostly express CD $8 \alpha \alpha$ homodimers but not CD $8 \alpha \beta$ heterodimers, i.e., unconventional CD $8 \alpha \alpha^{+}$ $\alpha \beta$ T cells and $\gamma \delta$ T cells.

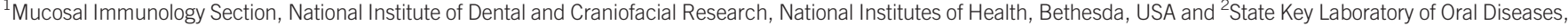
West China Hospital of Stomatology, Sichuan University, Chengdu, China

Correspondence: Dr W Chen, Mucosal Immunology Section, National Institute of Dental and Craniofacial Research, National Institutes of Health, Bethesda MD 20892, USA E-mail: wchen@mail.nih.gov

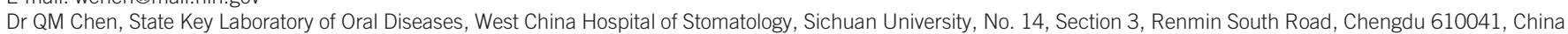
E-mail: qmchen@scu.edu.cn

Accepted 4 July 2014 


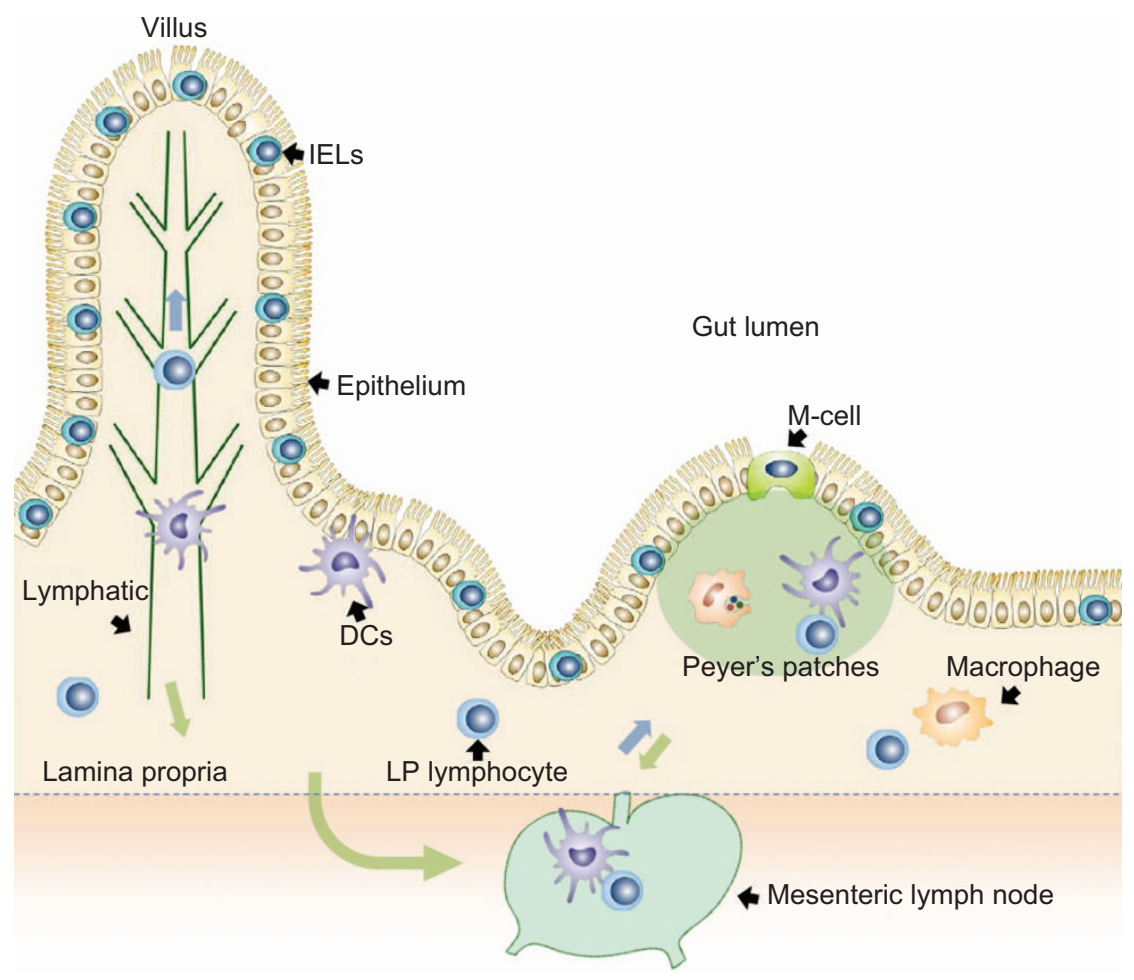

Figure 1 The overall scheme of the GI mucosal immune system. The GI mucosal immune system consists of three major compartments: epithelium, LP and gutassociated lymphoid tissue. IELs reside within the epithelium layer. DCs project dendrites into the epithelium to uptake antigens and migrate to the LP, secondary lymphoid tissue and draining lymph nodes, where they prime naive T cells. M-cells, located in the epithelium of Peyer's patches, pass the antigens to DCs, macrophages and other APCs. Naive T cells in secondary lymphoid tissues become activated after being primed by APCs and home to LP (called LPLs) or infiltrate into inflamed epithelium. APC, antigen presenting cell; DC, dendritic cell; GALT, gut-associated lymphoid tissue; GI, gastrointestinal; IEL, intraepithelial lymphocyte; LP, lamina propria; LPL, lamina propria lymphocyte; M-cell, microfold cell.

\section{T CELL SUBSETS AND FUNCTIONS IN MUCOSAL IMMUNITY}

\section{$\mathrm{T}_{\mathrm{H}}$ cells: differentiation and their functions}

The mucosa is a cytokine-rich environment where ECs, macrophages, dendritic cells (DCs) and T cells produce various types of cytokines, such as transforming growth factor (TGF)- $\beta$, interleukin (IL)-6, IL-10 and IL12. ${ }^{5}$ After TCR activation, naive $\mathrm{T}$ cells differentiate into different $\mathrm{T}_{\mathrm{H}}$ subsets depending on different cytokine milieu. These $\mathrm{T}_{\mathrm{H}}$ cells then exert either inflammatory or regulatory responses. ${ }^{6-8}$ During the past few decades, several $\mathrm{T}_{\mathrm{H}}$ subsets have been identified: $\mathrm{T}_{\mathrm{H}} 1, \mathrm{~T}_{\mathrm{H}} 2, \mathrm{~T}_{\mathrm{H}} 17$, $\mathrm{T}_{\mathrm{H}} 22, \mathrm{~T}_{\mathrm{H}}$, follicular helper $\mathrm{T}\left(\mathrm{T}_{\mathrm{fh}}\right)$ cells and regulatory $\mathrm{T}$ (Treg) cells. ${ }^{6,9}$ These subsets are characterized by the production of different effector cytokines and the expression of distinct transcription factors (Figure 2). Here, we focus on $\mathrm{T}_{\mathrm{H}}$ cells and Treg cells.

$\mathrm{T}_{\mathrm{H}} 1$ and $\mathrm{T}_{\mathrm{H}} 2$ cells were the first $\mathrm{T}_{\mathrm{H}}$ subsets described. ${ }^{10-11}$ In infections caused by intracellular pathogens, such as certain types of bacteria (e.g., Listeria monocytogenes) or viruses, macrophages, DCs and natural killer (NK) cells produce large amounts of IL-12 and interferon (IFN) $-\gamma$. These cytokines then drive $\mathrm{T}_{\mathrm{H}} 1$ cell differentiation through the activation of the signal transducer and activator of transcription (STAT) 1 and Janus kinase-STAT pathways. ${ }^{12}$ During $\mathrm{T}_{\mathrm{H}} 1$ cell differentiation, the transcription factor T-bet, which is the master transcription factor of $\mathrm{T}_{\mathrm{H}} 1$ cells, is induced through the STAT1 pathway, ${ }^{6}$ and T-bet expression has been shown to promote IFN- $\gamma$ production. ${ }^{11}$ IFN- $\gamma$ is a major effector cytokine of $\mathrm{T}_{\mathrm{H}} 1$ cells, which functions to recruit neutrophils and enhance antigen recognition and phagocytosis of intracellular microbes. ${ }^{11} \mathrm{~T}_{\mathrm{H}} 1$ cell cytokines also promote cytotoxic lymphocyte and NK cell responses that are critical to the cell-mediated immune responses in viral infections and tumour immunity. In addition, $\mathrm{T}_{\mathrm{H}} 1$ cells are also linked to the development of autoimmunity. Studies have demonstrated significantly elevated levels of IL-12, TNF- $\alpha$ and IFN- $\gamma$ in a mouse model of inflammatory bowel diseases (IBD), which is caused by unrestricted $\mathrm{T}_{\mathrm{H}} 1$ cell responses to commensal bacteria. ${ }^{13}$ Moreover, in autoimmune gastritis, considerable amounts of IL-12, TNF- $\alpha$ and IL- 6 are produced in chronic immune responses induced by Helicobacter pylori, which promotes $\mathrm{T}_{\mathrm{H}} 1$ cell differentiation. ${ }^{14}$

$\mathrm{T}_{\mathrm{H}} 2$ cell differentiation is initiated by TCR signalling together with IL-4 and subsequently by STAT6 signal transduction, leading to the expression of the transcription factor GATA-3. ${ }^{15}$ GATA- 3 is an activator of IL-4 and IL-13 and GATA-3 also induces its own expression, thus allowing $\mathrm{T}_{\mathrm{H}} 2$ cell stabilisation. ${ }^{6-7,10-11} \mathrm{~T}_{\mathrm{H}} 2$ cells contribute to the recruitment of leukocytes and macrophage activation by the secretion of IL- 4 and IL-13. $\mathrm{T}_{\mathrm{H}} 2$ cells also stimulate and increased mucus secretion from the epithelial cells of the airway and GI tract. The mucus layer protects the epithelium by trapping foreign particles and restricting microorganism colonisation. ${ }^{16-17} \mathrm{~T}_{\mathrm{H}} 2$ cells are crucial for resisting and eradicating helminthic infections. ${ }^{16-18} \mathrm{~T}_{\mathrm{H}} 2$ cell cytokines promote innate immune responses to worms by recruiting mast cells and basophils and inducing antibody production in $\mathrm{B}$ cells. ${ }^{16}$ Moreover, $\mathrm{T}_{\mathrm{H}} 2$ cell cytokines stimulate the production of mucins and anti-nematode protein resistin-like molecules. ${ }^{16}$ However, $\mathrm{T}_{\mathrm{H}} 2$ cells may also play a role in the pathogenesis of asthma, as increased numbers of $\mathrm{T}_{\mathrm{H}} 2$ cells in the airways of asthmatic patients have been observed. IL-4, IL- 5 and IL-13 produced by $\mathrm{T}_{\mathrm{H}} 2$ cells cause and maintain asthmatic pathophysiological features, such as allergic sensitisation and immunoglobulin (Ig) E production. ${ }^{19}$ 


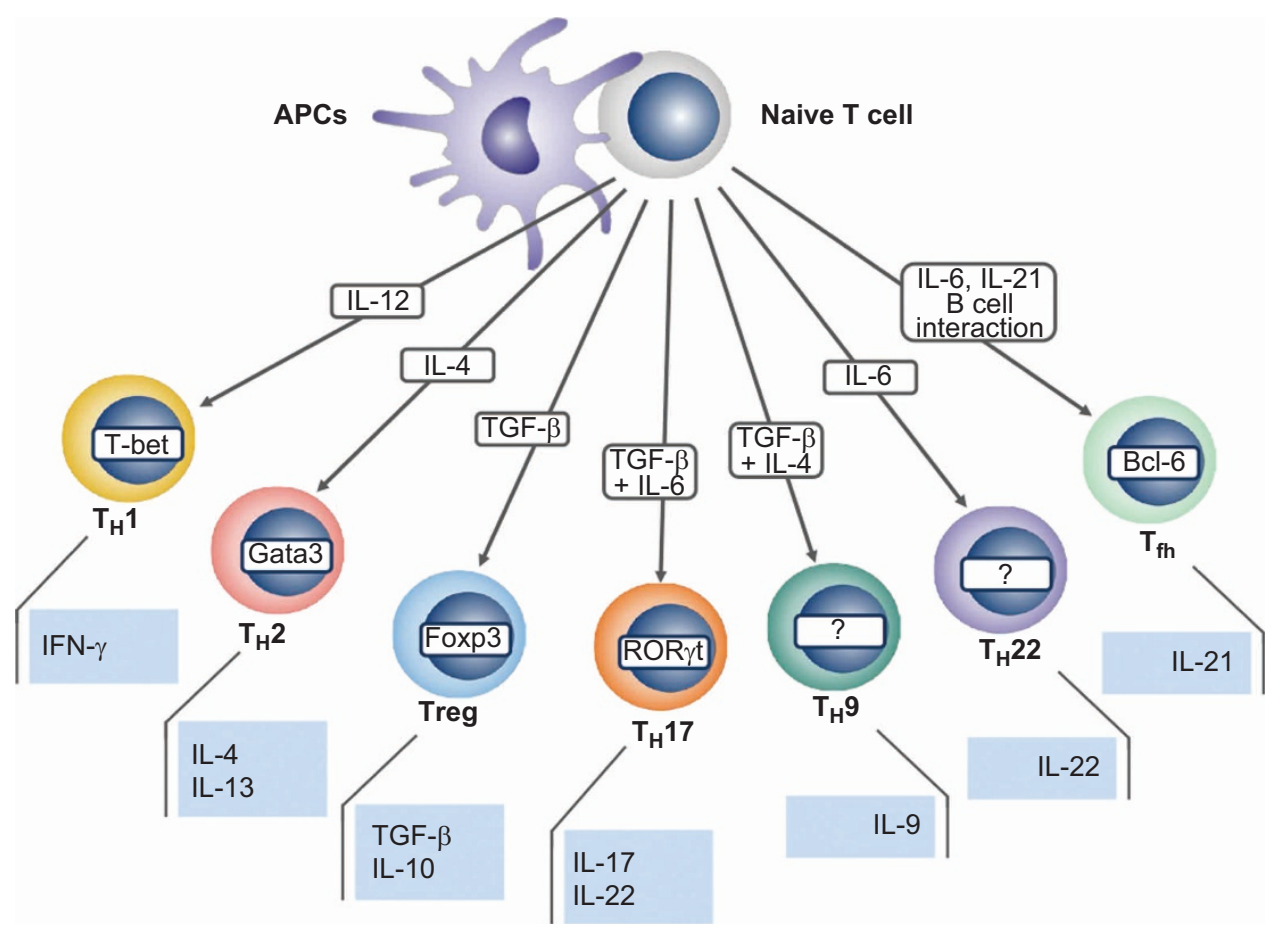

Figure 2 The paradigm of $T_{H}$ subsets and their cytokine profiles. After priming by APCs, naive $T$ cells begin proliferating and differentiating. $T_{H}$ differentiation depends on the cytokine environment. TGF- $\beta$ drives Treg cell generation; furthermore, in combination with IL- 6 or IL-4, TGF- $\beta$ also drives $T_{H} 17$ and $T_{H} 9$ cell differentiation, respectively. Cytokines initiate downstream signalling pathways to promote the expression of transcription factors such as the $T_{H} 1$ cell master transcription factor $\mathrm{T}$-bet and the $\mathrm{T}_{\mathrm{H}} 2$ cell master transcription factor GATA3. These transcription factors are indispensable for their key roles in $\mathrm{T}_{H}$ cell cytokine expression and $T_{H}$ cell function. APC, antigen presenting cell; IL, interleukin; INF, interferon; TGF, transforming growth factor; $T_{H}$, $T$ helper cell; Treg, regulatory $T$ cell.

$\mathrm{T}_{\mathrm{H}} 17$ cells are identified as an IL-17-producing $\mathrm{CD} 4{ }^{+} \mathrm{T}$ cell lineage and are regulated by two lineage-specific transcription factors-retinoic acid receptor-related orphan receptor (ROR) $\alpha$ and ROR $\gamma \mathrm{t} .^{20-22}$ TGF- $\beta$ and IL-6 promote the differentiation of $\mathrm{T}_{\mathrm{H}} 17$ cells in vivo and in vitro. ${ }^{20}$ $\mathrm{T}_{\mathrm{H}} 17$ cells exhibit potent pro-inflammatory functions due to their production of IL-17, which functions as a major anti-infection agent in defense against fungus. ${ }^{23}$ Many autoimmune diseases in humans have been found to be associated with $\mathrm{T}_{\mathrm{H}} 17$ cells, such as multiple sclerosis, rheumatoid arthritis, asthma and IBD. ${ }^{24}$ Interestingly, TGF- $\beta$ is found to induce both Foxp 3 and ROR $\gamma$ t expression, revealing that TGF- $\beta$ regulates the fine balance between Treg and $\mathrm{T}_{\mathrm{H}} 17$ cells. In addition, other factors, such as E2A (a member of the helix-loop-helix protein family) and retinoic acid, are also involved in controlling the balance between Treg and $\mathrm{T}_{\mathrm{H}} 17$ cells. ${ }^{5,25}$

$\mathrm{T}_{\mathrm{H}} 9$ cells were recently described as a new member of $\mathrm{T}_{\mathrm{H}}$ cell family. ${ }^{26}$ The differentiation of $\mathrm{T}_{\mathrm{H}} 9$ cells is induced by TGF- $\beta$ and IL-4. ${ }^{27} \mathrm{~T}_{\mathrm{H}} 9$ cells have similar functions as $\mathrm{T}_{\mathrm{H}} 2$ cells, but are distinguished by IL- 9 production. ${ }^{26-28}$ IL- 9 gene expression may be regulated in an epigenetic manner, carrying a 'poised' or bivalent mark in most activated T cells, and this mark can be activated by TGF- $\beta$ and silenced by IFN- $\gamma .{ }^{26}$ One study has proposed that PU.1 may be one of the key transcription factors for $\mathrm{T}_{\mathrm{H}} 9$ cell polarisation. ${ }^{29} \mathrm{~T}_{\mathrm{H}} 9$ cells are believed to be involved in airway inflammation because IL-9 is detected in $\mathrm{T}_{\mathrm{H}}$ cells that localized in asthmatic tissue. ${ }^{30}$ In addition, the expression of IL-9 causes airway inflammation and hyper-responsiveness. ${ }^{19}$ However, much work is required to address the development and biological significance of $\mathrm{T}_{\mathrm{H}} 9$ cells.

$\mathrm{T}_{\mathrm{H}} 22$ cells were initially identified as a group of $\mathrm{CD} 4^{+} \mathrm{CCR} 6^{+}$ memory $\mathrm{T}$ cells in the peripheral blood. $\mathrm{T}_{\mathrm{H}} 22$ cells also express the skin-homing chemokine receptors CCR4 and CCR10 and secrete IL22 upon stimulation. ${ }^{31-32} \mathrm{~T}_{\mathrm{H}} 22$ cells rarely produce IFN- $\gamma$ and IL-17 and express low or undetectable levels of T-bet, GATA3, and ROR $\gamma \mathrm{t}$, unlike other IL-22-producing cells such as $\mathrm{T}_{\mathrm{H}} 17$ and $\mathrm{T}_{\mathrm{H}} 1$ cells. ${ }^{11,32-33}$ $\mathrm{T}_{\mathrm{H}} 22$ cells can be induced in the presence of IL- 6 and TNF in vitro. Furthermore, plasmacytoid DCs can trigger the differentiation of $\mathrm{T}_{\mathrm{H}} 22$ cells. $^{32}$ Culture of naive $\mathrm{CD} 4^{+} \mathrm{T}$ cells from cord blood with IL-1 $\beta$ and IL-23, either in the presence or absence of IL-6, leads to the production of IL-22. ${ }^{32}$ The aryl hydrocarbon receptor is believed to be a vital transcription factor for IL-22 expression and $\mathrm{T}_{\mathrm{H}} 22$ differentiation. Because the majority of $\mathrm{T}_{\mathrm{H}} 22$ cells express CCR 4 and CCR10, it is likely that $\mathrm{T}_{\mathrm{H}} 22$ cells are crucial for skin immunity. ${ }^{34}$ IL-22 is an important cytokine against extracellular pathogens through synergising with other pro-inflammatory cytokines. ${ }^{35}$ Moreover, IL-22 receptors are expressed on many types of ECs. Subsequently, IL-22 can initiate and promote epithelial responses through IL-22 receptors. ${ }^{36}$ It has been suggested that IL-22 produced by $\mathrm{T}_{\mathrm{H}} 22$ and $\mathrm{T}_{\mathrm{H}} 17$ cells is critical for psoriasis pathogenesis because it induces hyperplasia, abnormal differentiation, and psoriatic gene expression on keratinocytes. However, IL-22 exhibits a protective role in IBD by enhancing epithelium integrity. ${ }^{37}$ Furthermore, $\mathrm{CD}^{+}{ }^{+} \mathrm{CD} 45 \mathrm{RB}^{\text {hi }} \mathrm{T}$ cells from IL-22-deficient mice result in more severe disease in an IBD mouse model. ${ }^{37-39}$

Notably, TGF- $\beta$, which is rich in the mucosal environment, plays a vital role in $\mathrm{T}$ cell differentiation. It is also important in maintaining immune balance within the GI tract. ${ }^{5}$ Furthermore, TGF- $\beta$ stimulates the production of IgA antibodies, which promotes the integrity of mucosal immunity. Treg cells are critical for the regulation of the immune response and T cell tolerance. ${ }^{40}$ TGF $\beta$ is indispensable for 
Treg cell induction and function. ${ }^{4-42}$ Moreover, Foxp3, the Treg cell master transcription factor, is induced by TGF- $\beta$ and plays a critical role in Treg cell development and function..$^{25,41,43-46}$ Treg cells inhibit the activity and immune response of numerous immune cells, including T cells and macrophages, by producing TGF- $\beta$ and IL- $10 .{ }^{47-48}$ Reports have demonstrated that TGF- $\beta$ signalling pathway is impaired in patients with Crohn's disease and other forms of IBD. ${ }^{4-5,42,49}$ IL-10 is another inhibitory cytokine that is important to mucosal environments. Mice lacking IL-10 exhibit colitis and severe GI pathology. IL-10 can be produced by Treg cells and is known to inhibit the activation of macrophages and DCs. IL-10 also suppresses the production of IL- 12 by activated macrophages and DCs, thus inhibiting $\mathrm{T}_{\mathrm{H}} 1$ cell differentiation. ${ }^{5,40,42,49}$

\section{IELs: a unique population in epithelium}

The IELs serve as the immune guardians at the frontline of the mucosal immune system. As discussed previously, the $\alpha \beta$ and $\gamma \delta$ IELs are the two major IELs. The $\gamma \delta$ T cell precursors mostly derive from thymocytes. ${ }^{2,50}$ In contrast to conventional $\alpha \beta$ T cells that mostly home into lymphoid tissues, $\gamma \delta$ T cells migrate directly to peripheral tissues, such as the cutaneous layer, GI tract, lungs and genital tracts, before birth and during the neonatal period. ${ }^{51-53}$ Hence, it is believed that $\gamma \delta \mathrm{T}$ cells contribute to immune protection immediately after birth. Unlike $\alpha \beta$ T cells, $\gamma \delta$ T cells perform their immune function in an 'innate-like' manner. Although $\gamma \delta$ T cells respond to antigens presented by MHC molecules, these cells are not restricted by MHC molecules. Activation of TCRs is triggered after $\gamma \delta$ T cells engage with MHC-like molecules (CD1d), MHC-related molecules (such as MR1 and CD1c), as well as MHC-unrelated molecules (such as pathogen-associated molecular patterns and danger-associated molecular patterns). ${ }^{51-52,54-55}$ Notably, $\gamma \delta$ T cells also express Toll-like receptors (TLRs) and NK receptors, including TLR2, TLR3, TLR4 and NKG2D. ${ }^{55}$ Therefore, these cells are believed to potentially sense cell stress and antigens directly. ${ }^{51-52}$ Moreover, it has been recently suggested that some $\gamma \delta \mathrm{T}$ cells (such as dendritic epidermal $\gamma \delta$ T cells) are responsible for wound healing and exhibit immune surveillance functions. ${ }^{56}$ Considerable amounts of $\gamma \delta$ IELs express CD8 $\alpha \alpha$ coreceptor in the GI tract and have been shown to perform either regulatory or pro-inflammatory functions. Intestinal $\gamma \delta$ IELs produce INF- $\gamma$ and TNF- $\alpha$ in response to infections and have been shown to promote inflammation in murine models of IBD. ${ }^{51,57-58}$ Interestingly, $\gamma \delta$ IELs can also play a regulatory role in the gut by producing IL- 10 and TGF- $\beta 1$, which suppresses INF- $\gamma$ production by effector T cells. ${ }^{51}$ Moreover, $\gamma \delta$ IELs protect the epithelial integrity by producing TGF- $\beta$ and keratinocyte growth factor. ${ }^{51,59}$

Another crucial IEL subset is TCR $\alpha \beta^{+} \mathrm{CD} 8 \alpha \alpha^{+}$IELs. As described earlier, these cells express coreceptor CD8 $\alpha \alpha$ homodimers. The presence of CD8 $\alpha \alpha$ homodimers is considered to be a hallmark of the activated phenotype, although CD8 $\alpha \alpha$ applies a suppressive signal to TCR activation. ${ }^{2,51,60}$ Studies have demonstrated that TCR $\alpha \beta^{+}$CD $8 \alpha \alpha^{+}$IELs are associated with intestinal antigen tolerance, immune regulation and antimicrobial function. ${ }^{51} \mathrm{~A}$ recent report has demonstrates that $\mathrm{TCR} \alpha \beta^{+} \mathrm{CD} 8 \alpha \alpha^{+}$IELs are derived from TCR $\alpha \beta^{+} \mathrm{CD} 4^{-} \mathrm{CD} 8^{-}$double negative thymocytes. ${ }^{61}$ Importantly, we have reported that TGF- $\beta$ controls the development of these CD $8 \alpha \alpha^{+}$intestinal IELs. $^{62}$ In addition, TGF- $\beta$ also induces CD8 $\alpha$ expression in peripheral CD $4^{+}$T cells to generate a $\mathrm{CD} 4{ }^{+} \mathrm{CD} 8 \alpha^{+}$double-positive IELs. ${ }^{16,62}$ Although the function of TCR $\alpha \beta^{+} \mathrm{CD} 8 \alpha \alpha^{+}$IELs remains largely unknown, they may possess immune regulatory functions through the production of TGF- $\beta$, lymphocyte activation gene 3 and other inhibitory molecules such as cytotoxic T lymphocyte-associated antigen, programmed cell death 1 and several inhibitory NK cell receptors (Table 1). ${ }^{51,63}$

\section{The oral-pharyngeal mucosal immune system}

The oral-pharyngeal mucosa shares many features with the gastrointestinal and respiratory tract yet has its own distinctive characteristics. Structurally, the oral-pharyngeal mucosa possesses a stratified squamous epithelium instead of a single layer epithelium. The LP underlying the epithelium is composed of loose connective tissue that contains blood and lymphatic vessels. Indeed, the oral-pharyngeal mucosa forms a mechanical barrier that is thicker and denser than gastrointestinal mucosa. However, the pharyngeal mucosa is nonetheless permeable and fragile. ${ }^{64-65}$ Uniquely, in the oral cavity, teeth extend through the mucosa; the periodontal epithelium surrounds teeth, forming an attachment and seal. However, the periodontal epithelium is a weak point for microorganism entry. Thus, a powerful oral-pharyngeal immune system is indispensable in safeguarding the integrity of the oral mucosa.

A proposed model of the oral-pharyngeal immune compartments suggests that they represent specialized MALT consisting of buccal mucosa, salivary glands and Waldeyer's ring (mainly composed by palatine tonsils and adenoids). ${ }^{66}$ However, others have suggested that the network of the oral-pharyngeal mucosal immune system resembles the gastrointestinal mucosal immune system and is composed of inductive and effector sites. The inductive sites include MALT (mainly consisting of tonsils and salivary glands), lymphoid follicles, and

Table 1 Notable T cell populations in the mucosal immune system

\begin{tabular}{|c|c|c|c|c|}
\hline Cell type & Markers & Induction/precursor & Major cytokine profile & References \\
\hline $\mathrm{T}_{\mathrm{H}} 1$ & TCR $\alpha \beta$, CD4, T-bet* & $\mathrm{IL}-12, \mathrm{IFN}-\gamma$ & $\mathrm{IFN}-\gamma$ & $6-7,10-12$ \\
\hline $\mathrm{T}_{H} 2$ & TCR $\alpha \beta$, CD4, GATA3* & IL-4 & IL-4, IL5, IL-13 & $6-7,10-12,15$ \\
\hline Treg & TCR $\alpha \beta$, CD4, CD25, Foxp3* & TGF- $\beta$, IL-2 & TGF- $\beta$, IL-10 & $25,41-42,45,47$ \\
\hline $\mathrm{T}_{\mathrm{H}} 17$ & TCR $\alpha \beta$, CD4, ROR $\gamma t^{*}$ & TGF- $\beta+$ IL- 6 & IL-17, IL-22 & $11,20-21,25,43,46$ \\
\hline $\mathrm{T}_{\mathrm{H}} 9$ & $\mathrm{TCR} \alpha \beta, \mathrm{CD} 4, \mathrm{PU} .1^{*}$ & TGF- $\beta+$ IL-4 & IL-9 & $6,26-30$ \\
\hline $\mathrm{T}_{\mathrm{H}} 22$ & TCR $\alpha \beta$, CD4 & $\mathrm{IL}-6, \mathrm{TNF}-\alpha$ & IL-22 & $6,31-34,39$ \\
\hline$T_{\text {fh }}$ & TCR $\alpha \beta$, CD4, CXCR5, Bcl-6* & IL-6, IL-21, B cells & IL-21, IL-10 & 9 \\
\hline $\mathrm{TCR} \alpha \beta^{+} \mathrm{CD} 8 \alpha \beta^{+}$IEL & $\mathrm{TCR} \alpha \beta, \mathrm{CD} 8 \alpha, \mathrm{CD} 8 \beta$ & Same as conventional T cells & Perforin, granzymes, IFN- $\gamma$ & $2,4,51,57,61-62$ \\
\hline $\mathrm{TCR} \alpha \beta^{+} \mathrm{CD} 8 \alpha \alpha^{+}$IEL & $\mathrm{TCR} \alpha \beta, \mathrm{CD} 8 \alpha$ & $\begin{array}{l}\text { TCR } \alpha \beta^{+} \mathrm{CD} 4^{-} \mathrm{CD}^{-} \text {thymocytes, TGF- } \beta \\
\text { controls the development }\end{array}$ & TGF- $\beta$, IL-10 & $2,4,51,57,61-62$ \\
\hline$\gamma \delta \mathrm{IEL}$ & $\mathrm{TCR} \gamma \delta(\mathrm{CD} 8 \alpha)$ & $\mathrm{TCR} \gamma \delta^{+} \mathrm{CD}^{-} \mathrm{CD}^{-}$thymocytes & TGF- $\beta$, IFN- $\gamma$, IL-10, IL-17 & $2,4,50-53$ \\
\hline
\end{tabular}

IEL, intraepithelial lymphocyte; IL, interleukin; IFN, interferon; ROR, receptor-related orphan receptor; TCR, T cell receptor; TGF, transforming growth factor; $\mathrm{T}_{\mathrm{H}}$, T helper cell; $T_{\text {fh }}$, follicular helper $T$ cell.

* Intracellular markers and transcription factors. 


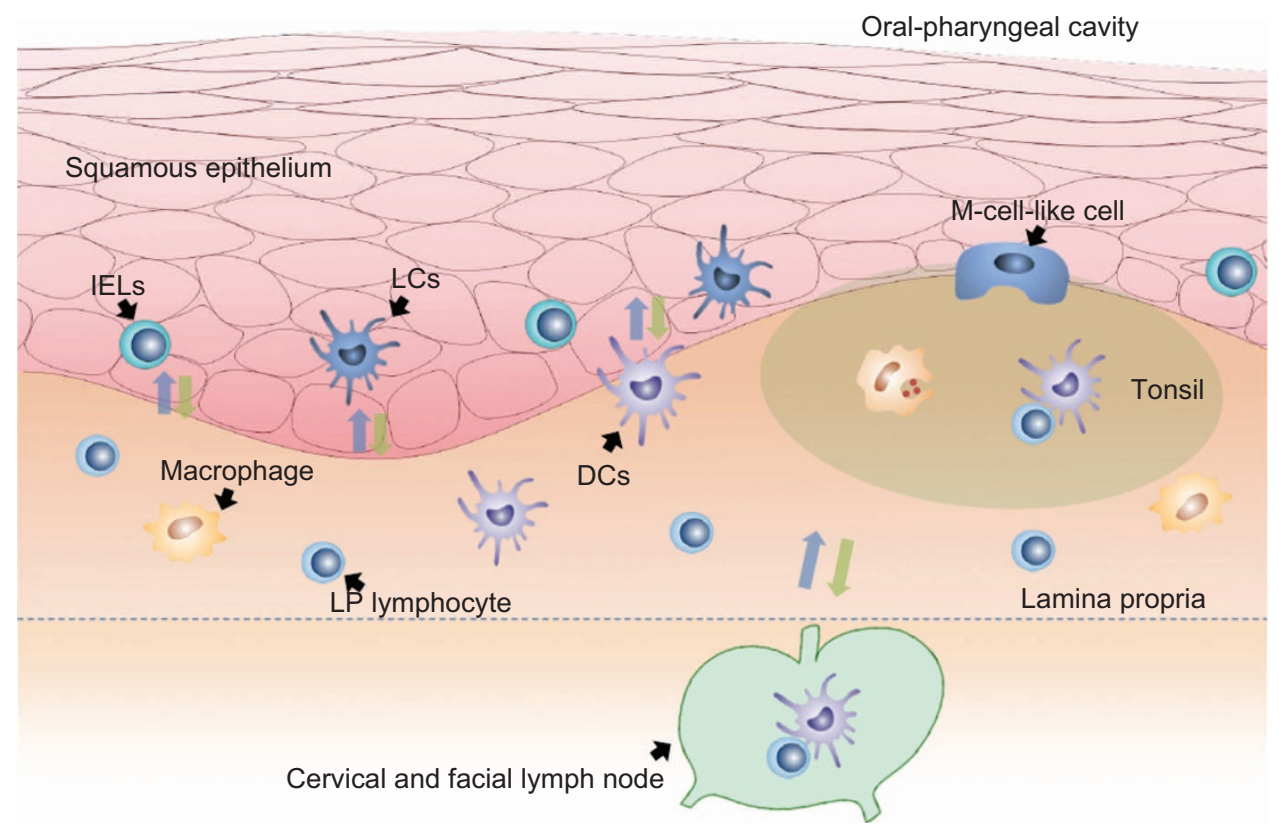

Figure 3 The structures and immune cells in the oral immune system. The oral-pharyngeal immune system shares similar anatomical compartments of other mucosal immune system. The oral mucosa consists of stratified squamous epithelium, LP and MALTs. DCs, LCs and IELs reside in the epithelial layer. DCs in the LP project dendrites into the epithelium to uptake antigens and migrate to secondary lymphoid tissue and draining lymph nodes. MALTs in the oral-pharyngeal cavity are located in the tonsils and are organized lymphoid follicles. M-cell-like cells in the tonsil epithelium also function to transfer antigens to APCs. APC, antigen presenting cell; DC, dendritic cell; IEL, intraepithelial lymphocyte; LP, lamina propria; MALT, mucosal-associated lymphoid tissue; M-cell, microfold cell.

draining lymph nodes. In contrast, the effector sites include epithelium, LP and salivary glands. ${ }^{65,67}$ The inductive sites are where most lymphocytes are activated and expanded upon antigen stimulation. On the contrary, the effector sites are where activated lymphocytes migrate and relocate to mediate immune responses. ${ }^{68}$

Compartmentalized immune cells, such as IELs and LP lymphocytes, undertake the elimination of foreign antigens. After antigen uptake, DCs, macrophages and Langerhans cells (LCs) residing in the epithelium or LP migrate into MALT and draining lymph nodes and initiate the adaptive immune responses by inducing $\mathrm{T}$ cell proliferation and differentiation. ${ }^{69-70}$ In addition, a group of M-cell-like cells has been identified in the epithelium of palatine tonsil crypt that is responsible for luminal antigen uptake. ${ }^{65-66}$ The mucosa is described as a 'slippery ground ${ }^{17}$ that is covered with mucus. In the oral cavity, the mucosa is covered with saliva that contains immunoglobulins, such as secretory IgA, antimicrobial peptides such as defensins, and enzymes secreted by salivary glands (Figure 3). ${ }^{17,64,66,71-72}$

Among the immune cells in the oral-pharyngeal mucosa, DCs are relatively better studied. ${ }^{65,73}$ In in murine models, different subsets of $\mathrm{CD}_{11 \mathrm{c}^{+}}$DCs, as well as LCs reside in the epithelium of buccal, sublingual and gingival mucosa. DCs and LCs are APCs; thus, in oral mucosa, DCs are responsible for antigen capture and antigen presentation to T cells. Compared with DCs and LCs, T cell populations such as IELs in the oral-pharyngeal mucosa are less studied. In patients with dermatitis herpetiformis, the $\alpha \beta$ and $\gamma \delta$ T cells reside in the epithelium of oral mucosa. ${ }^{74-75}$ However, CD $8 \alpha \alpha^{+}$IELs in the oral-pharyngeal mucosa have not been identified and characterized until recently (RQ $\mathrm{Wu}$ and $\mathrm{W}$ Chen, in preparation).

\section{Oral mucosal diseases with immunopathogenesis}

In clinics, various mucosal diseases have been observed in the oral cavity, including viral infection, candida infection and oral lichen planus (OLP). These mucosal diseases are mainly caused by immune deficiency and/or the dysregulation of the oral immune system. In particular, $\mathrm{T}$ cells have been suggested to be associated with the development of these diseases, yet their causative roles have not been established. In this section, we highlight the recent findings on the roles of $\mathrm{T}$ cells in oral mucosal diseases.

An example of mucosal immune system dysfunction can be observed in human immunodeficiency virus (HIV)-infected individuals. HIV infection leads to low levels of $\mathrm{CD}^{+}{ }^{+} \mathrm{T}$ cells and results in immune deficiency. ${ }^{76}$ People infected with HIV are highly susceptible to infection by oral and pharyngeal commensal bacteria and fungi such as Candida albicans due to the weakening of the $\mathrm{T}_{\mathrm{H}}$ cell response. ${ }^{66,77-78}$ Another example is hyper-IgE syndrome, which results from STAT3 mutations. Patients with hyper-IgE syndrome suffer from oral candidiasis due to a deficiency of $\mathrm{T}_{\mathrm{H}} 17$ cells, ${ }^{79}$ consistent with animal studies demonstrating that mice with $\mathrm{T}_{\mathrm{H}} 17$-deficiency (IL$23 \mathrm{p} 19^{-1-}$ mice) and IL-17 receptor-deficiency (IL-17RA ${ }^{-1-}$ mice) develop severe Candida albicans infection in the oral cavity. ${ }^{80}$ Although $\mathrm{T}_{\mathrm{H}} 17$ cells are important for oral immune responses against fungus, evidence suggests that aberrant or uncontrolled $\mathrm{T}_{\mathrm{H}} 17$ cell responses result in chronic inflammation towards candidiasis, which ultimately results in autoimmunity. ${ }^{77,81}$

Immune responses to food antigens and commensal bacteria generally do not induce any inflammation but do induce immune tolerance. Autoimmune diseases may occur as a result of unrestricted immune responses to commensal bacteria. Many inflammatory and autoimmune diseases have been shown to develop in the oral mucosa, such as periodontitis, Sjögren's syndrome and OLP. Periodontitis is initiated by the accumulation of bacterial plaque, subsequent tissue damage and bone loss due to host immune responses and inappropriate inflammation. $\mathrm{T}_{\mathrm{H}}$ cells are found to play an important role in the recruitment of neutrophils and osteoclasts. Consequently, the gingival 
barriers are destroyed together with the retraction of gingiva and destruction of alveolar bone. ${ }^{82-83}$ OLP, a chronic inflammatory disease, is characterized by massive lymphocyte infiltration in the LP and results in chronic destruction of the epithelium basal layer. ${ }^{84-86}$ Scully et al. ${ }^{75,85,87-88}$ suggested that $\mathrm{T}_{\mathrm{H}} 1$ and $\mathrm{T}_{\mathrm{H}} 2$ cells contribute to inflammation and mucosal lesion formation in OLP. Pro-inflammatory cytokines, including IL-6, IL-17 and TNF- $\alpha$, are increased in the saliva and serum of OLP patients. ${ }^{89-90}$ On the contrary, TGF$\beta$ is decreased in the serum of OLP patients compared with that of healthy individuals. ${ }^{91}$ A single nucleotide polymorphism study on IL-10 polymorphisms revealed higher frequencies of four haplotypes (including - $1082 \mathrm{G} / \mathrm{A},-819 \mathrm{C} / \mathrm{T}$ and $-592 \mathrm{C} / \mathrm{A}$ polymorphisms) in the peripheral blood of OLP patients, that correlated with a lower serum IL-10 level. ${ }^{92}$ Based on these findings, some reports have suggested that $\mathrm{T}$ cells might be involved in OLP development. Nevertheless, given that many immune cell types are capable of producing these cytokines, the roles of $\mathrm{T}$ cells in the pathogenesis of OLP remain be determined.

Oral mucosal tolerance is defined as immune tolerance induced by oral mucosa. ${ }^{65}$ Oral mucosal tolerance is distinct from 'oral tolerance', which is tolerance induced within the GI mucosal immune system. Oral mucosal tolerance induced by sublingual immunotherapy is a promising therapeutic for allergy, such as rhinitis. ${ }^{93-94}$ Upon antigen stimulation and immunisation via sublingual mucosa, DCs induce the generation of Treg cells by producing TGF- $\beta$ and other mediators, such as indoleamine 2,3dioxygenase. ${ }^{65,93,95}$ Cytokines produced by Treg cells, such as IL10 and TGF- $\beta$, and inhibitory ligands expressed on Treg cells, such as CTLA-4, can limit $\mathrm{T}_{\mathrm{H}}$ cell responses. ${ }^{48,96}$ In addition, constitutively expressed inhibitory molecules on DCs and LCs such as B7-H molecules are responsible for oral mucosal tolerance. ${ }^{65}$ Studies have indicated that the intraoral administration of a $\mathrm{T}$ cell epitope peptide via the mucosa prior to allergen challenge limited $\mathrm{T}$ cell proliferation in oral-pharyngeal draining lymph nodes. ${ }^{97}$ Furthermore, studies have demonstrated that greater $\mathrm{T}$ cell suppression is induced by intraoral instead of intragastric administration, which suggests that 'oral mucosal tolerance' is more effective than 'oral tolerance'. ${ }^{97}$

\section{CONCLUDING REMARKS}

In this review, we have discussed the mucosal immune systems in terms of its structure, cell components, and protective mechanisms based on our knowledge of the GI mucosal immune system. We have also summarized current findings on the development and differentiation of $\mathrm{T}_{\mathrm{H}}$ cells and IELs. In addition, we review recent advances in our understanding of the oral-pharyngeal mucosal immune system. It is well established that in the gut mucosal immune system, compartmentalized immune cells constitute an effective and dynamic network in which numerous types of cells and molecules contribute to the balance between immune tolerance and immune response. Studies on animal disease models such as colitis and IBD illustrate an altered pathological status of the immune system. In addition, in the oral mucosa, ECs and immune cells produce a wide range of cytokines, including IL-1 $\beta$, IL-6, TNF- $\alpha$, granulocyte-monocyte colony-stimulating factor and TGF- $\beta,{ }^{65,84,98}$ which contribute to an environment that impacts $\mathrm{T}$ cell activation, proliferation and differentiation. However, much work is required for a clear understanding of $\mathrm{T}$ cell subsets and their function in the oral pharyngeal immune system. Therefore, in the future, it is important to focus our attention on the oral mucosal $\mathrm{T}_{\mathrm{H}}$ cell diversity, $\mathrm{T}$ cell networks and $\mathrm{T}$ cell functions under both healthy and pathological conditions.

\section{ACKNOWLEDGEMENTS}

This work was supported by the Intramural Research Program of the National Institutes of Health, National Institute of Dental and Craniofacial Research, USA. This work was also supported by grant 2012DFA31370 from the International S\&T Cooperation Program of China and the National Nature Science Foundation of China (81321002). The authors would like to express their apology for omitting many important primary articles due to the space limitations. We also thank Dr Cheryl Chia for critical reading and suggestions for the manuscript.

1 Murphy KP. Janeway's immunobiology. 8th ed. London/New York: Garland Science, Taylor \& Francis Group, 2011: 465-466.

2 van Wijk F, Cheroutre $\mathrm{H}$. Intestinal T cells: facing the mucosal immune dilemma with synergy and diversity. Semin Immunol 2009; 21(3): 130-138.

3 Dobbins WO 3rd. Human intestinal intraepithelial lymphocytes. Gut 1986; 27(8): 972-985.

4 van Wijk F, Cheroutre H. Mucosal T cells in gut homeostasis and inflammation. Expert Rev Clin Immunol 2010; 6(4): 559-566.

5 Konkel JE, Chen W. Balancing acts: the role of TGF- $\beta$ in the mucosal immune system. Trends Mol Med 2011; 17(11): 668-676.

6 O'Shea JJ, Paul WE. Mechanisms underlying lineage commitment and plasticity of helper CD4 ${ }^{+}$T cells. Science 2010; 327(5969): 1098-1102.

7 Zhou L, Chong MM, Littman DR. Plasticity of CD4 ${ }^{+} \mathrm{T}$ cell lineage differentiation. Immunity 2009; 30(5): 646-655.

8 Abbas AK, Murphy KM, Sher A. Functional diversity of helper T lymphocytes. Nature 1996; 383(6603): 787-793.

9 Ma CS, Deenick EK, Batten M et al. The origins, function, and regulation of T follicular helper cells. J Exp Med 2012; 209(7): 1241-1253.

10 Amsen D, Spilianakis CG, Flavell RA. How are $T_{H} 1$ and $T_{H} 2$ effector cells made? Curr Opin Immunol 2009; 21(2): 153-160.

11 Dong C, Flavell RA. Control of T helper cell differentiation-in search of master genes. Sci STKE 2000; 2000(49): pe1.

12 Trinchieri G. Interleukin-12 and the regulation of innate resistance and adaptive immunity. Nat Rev Immunol 2003; 3(2): 133-146.

13 Powrie F, Leach MW, Mauze S et al. Inhibition of Th1 responses prevents inflammatory bowel disease in scid mice reconstituted with $\mathrm{CD}_{45 \mathrm{RB}^{\text {hi }}} \mathrm{CD}^{+}{ }^{+} \mathrm{T}$ cells. Immunity 1994; 1(7): 553-562.

14 Tu E, Ang DK, Bellingham SA et al. Both IFN- $\gamma$ and IL-17 are required for the development of severe autoimmune gastritis. Eur J Immunol 2012; 42(10): 2574 2583.

15 Ouyang W, Ranganath SH, Weindel $\mathrm{K}$ et al. Inhibition of Th1 development mediated by GATA-3 through an IL-4-independent mechanism. Immunity 1998; 9(5): 745-755.

16 Anderson MK. Changing course by lymphocyte lineage redirection. Nat Immunol 2013; 14(3): 199-201.

17 Brandtzaeg P, Pabst R. Let's go mucosal: communication on slippery ground. Trends Immunol 2004; 25(11): 570-577.

18 Taylor MD, van der Werf N, Maizels RM. T cells in helminth infection: the regulators and the regulated. Trends Immunol 2012; 33(4): 181-189.

19 Lloyd CM, Hessel EM. Functions of T cells in asthma: more than just $\mathrm{T}_{\mathrm{H}} 2$ cells. Nat Rev Immunol 2010; 10(12): 838-848.

20 Dong C. Diversification of T-helper-cell lineages: finding the family root of IL-17producing cells. Nat Rev Immunol 2006; 6(4): 329-333.

21 Dong C. TH17 cells in development: an updated view of their molecular identity and genetic programming. Nat Rev Immunol 2008; 8(5): 337-348.

22 Schambach F, Schupp M, Lazar MA et al. Activation of retinoic acid receptor-alpha favours regulatory $\mathrm{T}$ cell induction at the expense of IL-17-secreting $\mathrm{T}$ helper cell differentiation. Eur J Immunol 2007; 37(9): 2396-2399.

23 Bettelli E, Oukka M, Kuchroo VK. $\mathrm{T}_{\mathrm{H}^{-}}-17$ cells in the circle of immunity and autoimmunity. Nat Immunol 2007; 8(4): 345-350.

24 Ghoreschi K, Laurence A, Yang XP et al. Generation of pathogenic $T_{H} 17$ cells in the absence of TGF- $\beta$ signalling. Nature 2010; 467(7318): 967-971.

25 Maruyama T, Li J, Vaque JP et al. Control of the differentiation of regulatory T cells and $\mathrm{T}_{\mathrm{H}} 17$ cells by the DNA-binding inhibitor Id3. Nat Immunol 2011; 12(1): 86-95.

26 Locksley RM. Nine lives: plasticity among T helper cell subsets. J Exp Med 2009, 206(8): 1643-1646.

27 Veldhoen M, Uyttenhove C, van Snick J et al. Transforming growth factor-beta 'reprograms' the differentiation of T helper 2 cells and promotes an interleukin 9producing subset. Nat Immunol 2008; 9(12): 1341-1346.

28 Schmitt E, Germann T, Goedert S et al. IL-9 production of naive CD4 ${ }^{+}$T cells depends on IL-2, is synergistically enhanced by a combination of TGF-beta and IL-4, and is inhibited by IFN-gamma. J Immunol 1994; 153(9): 3989-3996. 
29 Chang HC, Sehra S, Goswami R et al. The transcription factor PU.1 is required for the development of IL-9-producing T cells and allergic inflammation. Nat Immuno/2010; 11(6): 527-534.

30 Temann UA, Geba GP, Rankin JA et al. Expression of interleukin 9 in the lungs of transgenic mice causes airway inflammation, mast cell hyperplasia, and bronchial hyperresponsiveness. J Exp Med 1998; 188(7): 1307-1320.

31 Duhen T, Geiger R, Jarrossay D et al. Production of interleukin 22 but not interleukin 17 by a subset of human skin-homing memory T cells. Nat Immunol 2009; 10(8): 857-863.

32 Trifari S, Kaplan CD, Tran EH et al. Identification of a human helper T cell population that has abundant production of interleukin 22 and is distinct from $T_{H^{-}} 17, T_{H} 1$ and $\mathrm{T}_{\mathrm{H}} 2$ cells. Nat Immunol 2009; 10(8): 864-871.

33 Bird PI, Trapani JA, Villadangos JA. Endolysosomal proteases and their inhibitors in immunity. Nat Rev Immunol 2009; 9(12): 871-882.

34 Sonnenberg GF, Fouser LA, Artis D. Border patrol: regulation of immunity, inflammation and tissue homeostasis at barrier surfaces by IL-22. Nat Immunol 2011; 12(5): 383-390.

35 Basu R, O'Quinn DB, Silberger DJ et al. Th22 cells are an important source of IL-22 for host protection against enteropathogenic bacteria. Immunity 2012; 37(6): 10611075.

36 Boniface K, Bernard FX, Garcia M et al. IL-22 inhibits epidermal differentiation and induces proinflammatory gene expression and migration of human keratinocytes. J Immunol 2005; 174(6): 3695-3702.

37 Zenewicz LA, Yancopoulos GD, Valenzuela DM et al. Innate and adaptive interleukin22 protects mice from inflammatory bowel disease. Immunity 2008; 29(6): 947957

38 Ouyang W, Valdez P. IL-22 in mucosal immunity. Mucosal Immuno/2008; 1(5): 335 338.

39 Ouyang W. Distinct roles of IL-22 in human psoriasis and inflammatory bowel disease. Cytokine Growth Factor Rev 2010; 21(6): 435-441.

40 Chen W. Tregs in immunotherapy: opportunities and challenges. Immunotherapy 2011; 3(8): 911-914.

41 Chen W, Jin W, Hardegen N et al. Conversion of peripheral CD4 ${ }^{+} \mathrm{CD} 25^{-}$naive $\mathrm{T}$ cells to $\mathrm{CD} 4{ }^{+} \mathrm{CD} 25^{+}$regulatory T cells by TGF-beta induction of transcription factor Foxp3. J Exp Med 2003; 198(12): 1875-1886.

42 Chen W, Konkel JE. TGF-beta and 'adaptive' Foxp3 ${ }^{+}$regulatory T cells. J Mol Cell Biol 2010; 2(1): 30-36

43 Liu Y, Zhang P, Li J et al. A critical function for TGF-beta signaling in the development of natural $\mathrm{CD}^{+}{ }^{+} \mathrm{CD} 25^{+}$Foxp $^{+}$regulatory T cells. Nat Immunol 2008; 9(6): 632 640.

44 Maruyama T, Konkel JE, Zamarron BF et al. The molecular mechanisms of Foxp3 gene regulation. Semin Immunol 2011; 23(6): 418-423.

45 Perruche S, Zhang P, Liu Y et al. CD3-specific antibody-induced immune tolerance involves transforming growth factor-beta from phagocytes digesting apoptotic T cells. Nat Med 2008; 14(5): 528-535.

46 Josefowicz SZ, Rudensky A. Control of regulatory T cell lineage commitment and maintenance. Immunity 2009; 30(5): 616-625.

47 Sakaguchi S. Regulatory T cells: key controllers of immunologic self-tolerance. Cell 2000; 101(5): 455-458.

48 Chen W, Jin W, Wahl SM. Engagement of cytotoxic T lymphocyte-associated antigen 4 (CTLA-4) induces transforming growth factor beta (TGF-beta) production by murine CD4 $^{+}$T cells. J Exp Med 1998; 188(10): 1849-1857.

49 Wahl SM, Vázquez N, Chen W. Regulatory T cells and transcription factors gatekeepers in allergic inflammation. Curr Opin Immunol 2004; 16(6): 768774.

50 Carpenter AC, Bosselut R. Decision checkpoints in the thymus. Nat Immunol 2010; 11(8): 666-673.

51 Cheroutre H, Lambolez F, Mucida D. The light and dark sides of intestinal intraepithelial lymphocytes. Nat Rev Immunol 2011; 11(7): 445-456.

52 Carding SR, Egan PJ. Gammadelta T cells: functional plasticity and heterogeneity. Nat Rev Immunol 2002; 2(5): 336-345.

53 Ciofani M, Zúñiga-Pflücker JC. Determining $\gamma \delta$ versus $\alpha \beta$ T cell development. Nat Rev Immunol 2010; 10(9): 657-663.

54 Vantourout P, Hayday A. Six-of-the-best: unique contributions of $\gamma \delta \mathrm{T}$ cells to immunology. Nat Rev Immunol 2013; 13(2): 88-100.

55 Bonneville M, O'Brien RL, Born WK. $\gamma \delta$ T cell effector functions: a blend of innate programming and acquired plasticity. Nat Rev Immunol 2010; 10(7): 467478

56 Jameson J, Ugarte K, Chen $\mathrm{N}$ et al. A role for skin $\gamma \delta$ T cells in wound repair. Science 2002; 296(5568): 747-749.

57 Simpson SJ, Holländer GA, Mizoguchi E et al. Expression of pro-inflammatory cytokines by TCR $\alpha \beta^{+}$and TCR $\gamma \delta^{+}$T cells in an experimental model of colitis. Eur J Immunol 1997; 27(1): 17-25.

58 Kanazawa $\mathrm{H}$, Ishiguro $\mathrm{Y}$, Munakata A et al. Multiple accumulation of $\mathrm{V} \delta 2^{+} \gamma \delta \mathrm{T}$-cel clonotypes in intestinal mucosa from patients with Crohn's disease. Dig Dis Sci2001; 46(2): 410-416.

59 Shires J, Theodoridis E, Hayday AC. Biological insights into TCR $\gamma \delta^{+}$and TCR $\alpha \beta^{+}$ intraepithelial lymphocytes provided by serial analysis of gene expression (SAGE). Immunity 2001; 15(3): 419-434.

60 Cawthon AG, Lu H, Alexander-Miller MA. Peptide requirement for CTL activation reflects the sensitivity to $C D 3$ engagement: correlation with $C D 8 \alpha \beta$ versus $C D 8 \alpha \alpha$ expression. J Immunol 2001; 167(5): 2577-2584.
61 Gangadharan D, Lambolez F, Attinger A et al. Identification of pre- and postselection TCR $\alpha \beta^{+}$intraepithelial lymphocyte precursors in the thymus. Immunity 2006; 25(4): 631-641.

62 Konkel JE, Maruyama T, Carpenter AC et al. Control of the development of CD8 $\alpha \alpha^{+}$ intestinal intraepithelial lymphocytes by TGF- $\beta$. Nat Immunol 2011; 12(4): 312 319.

63 Denning TL, Granger SW, Granger S et al. Mouse TCR $\alpha \beta^{+} \operatorname{CD} 8 \alpha \alpha$ intraepithelial lymphocytes express genes that down-regulate their antigen reactivity and suppress immune responses. J Immunol 2007; 178(7): 4230-4239.

64 Walker DM. Oral mucosal immunology: an overview. Ann Acad Med Singap 2004; 33(4 Suppl): 27-30

65 Novak N, Haberstok J, Bieber T et al. The immune privilege of the oral mucosa. Trends Mol Med 2008; 14(5): 191-198.

66 Lü FX, Jacobson RS. Oral mucosal immunity and HIV/SIV infection. J Dent Res 2007 86(3): 216-226.

67 Kiyono H, Fukuyama S. NALT- versus Peyer's-patch-mediated mucosal immunity. Nat Rev Immunol 2004; 4(9): 699-710.

68 Zuercher AW, Coffin SE, Thurnheer MC et al. Nasal-associated lymphoid tissue is a mucosal inductive site for virus-specific humoral and cellular immune responses. J Immunol 2002; 168(4): 1796-1803.

69 Barrett AW, Cruchley AT, Williams DM. Oral mucosal Langerhans' cells. Crit Rev Oral Biol Med 1996; 7(1): 36-58.

70 Cutler CW, Jotwani R. Dendritic cells at the oral mucosal interface. J Dent Res 2006; 85(8): 678-689

71 Dale BA, Fredericks LP. Antimicrobial peptides in the oral environment: expression and function in health and disease. Curr Issues Mol Biol 2005; 7(2): 119-133.

72 Gomes Pde S, Fernandes MH. Defensins in the oral cavity: distribution and biological role. J Oral Pathol Med 2010; 39(1): 1-9.

73 Hovav AH. Dendritic cells of the oral mucosa. Mucosal Immunol 2014; 7(1): 27 37.

74 Patinen P, Savilahti E, Hietanen J et al. Intraepithelial lymphocytes bearing the $\gamma / \delta$ receptor in the oral and jejunal mucosa in patients with dermatitis herpetiformis. Eur $J$ Oral Sci 1997; 105(2): 130-135.

75 Walton LJ, Macey MG, Thornhill MH et al. Intra-epithelial subpopulations of T lymphocytes and Langerhans cells in oral lichen planus. J Oral Pathol Med 1998, 27(3): 116-123.

76 Cohen MS, Shaw GM, McMichael AJ et al. Acute HIV-1 Infection. N Engl J Med 2011 364(20): 1943-1954.

77 Romani L. Immunity to fungal infections. Nat Rev Immunol 2011; 11(4): 275288.

78 Huang W, Na L, Fidel PL et al. Requirement of interleukin-17A for systemic anti-Candida albicans host defense in mice. J Infect Dis 2004; 190(3): 624631.

79 Conti HR, Baker O, Freeman AF et al. New mechanism of oral immunity to mucosal candidiasis in hyper-lgE syndrome. Mucosal Immunol 2011; 4(4): 448455.

80 Conti HR, Shen F, Nayyar N et al. Th17 cells and IL-17 receptor signaling are essential for mucosal host defense against oral candidiasis. J Exp Med 2009; 206(2): 299311.

81 Cheng SC, van de Veerdonk F, Smeekens S et al. Candida albicans dampens host defense by downregulating IL-17 production. J Immunol 2010; 185(4): 2450 2457.

82 Cochran DL. Inflammation and bone loss in periodontal disease. J Periodonto/ 2008 79(8 Suppl): 1569-1576.

83 Gemmell E, Yamazaki K, Seymour GJ. Destructive periodontitis lesions are determined by the nature of the Iymphocytic response. Crit Rev Oral Biol Med 2002; 13(1): 17-34.

84 Wu RQ, Zhao XF, Wang ZY et al. Novel molecular events in oral carcinogenesis via integrative approaches. J Dent Res 2011; 90(5): 561-572.

85 Scully C, Carrozzo M. Oral mucosal disease: lichen planus. Br J Oral Maxillofac Surg 2008; 46(1): 15-21.

86 Dan H, Liu W, Zhou $Y$ et al. Association of interleukin-8 gene polymorphisms and haplotypes with oral lichen planus in a Chinese population. Inflammation 2010; 33(2): 76-81.

87 Rhodus NL, Cheng B, Ondrey F. Th1/Th2 cytokine ratio in tissue transudates from patients with oral lichen planus. Mediators Inflamm 2007; 2007: 19854.

88 Bai J, Lin M, Zeng X et al. Association of polymorphisms in the human IFN- $\gamma$ and IL-4 gene with oral lichen planus: a study in an ethnic Chinese cohort. J Interferon Cytokine Res 2008; 28(6): 351-358.

89 Zhang Y, Lin M, Zhang S et al. NF-kB-dependent cytokines in saliva and serum from patients with oral lichen planus: a study in an ethnic Chinese population. Cytokine 2008; 41(2): 144-149.

90 Zhang Y, Liu W, Zhang S et al. Salivary and serum interleukin-18 in patients with ora lichen planus: a study in an ethnic Chinese population. Inflammation 2012; 35(2): 399-404.

91 Taghavi Zenouz A, Pouralibaba F, Babaloo Z etal. Evaluation of serum TNF- $\alpha$ and TGF$\beta$ in patients with oral lichen planus. J Dent Res Dent Clin Dent Prospects 2012; 6(4): 143-147.

92 Bai J, Jiang L, Lin M et al. Association of polymorphisms in the tumor necrosis factor- $\alpha$ and interleukin-10 genes with oral lichen planus: a study in a Chinese cohort with Han ethnicity. J Interferon Cytokine Res 2009; 29(7): 381-388. 
93 Novak N, Gros E, Bieber T et al. Human skin and oral mucosal dendritic cells as 'good guys' and 'bad guys' in allergic immune responses. Clin Exp Immunol 2010; 161(1): 28-33.

94 Mascarell L, Saint-Lu N, Moussu H et al. Oral macrophage-like cells play a key role in tolerance induction following sublingual immunotherapy of asthmatic mice. Mucosal Immunol 2011; 4(6): 638-647.

95 Chen W. IDO: more than an enzyme. Nat Immunol 2011; 12(9): 809-811.

96 Bohle B, Kinaciyan T, Gerstmayr M et al. Sublingual immunotherapy induces IL-10producing $\mathrm{T}$ regulatory cells, allergen-specific $\mathrm{T}$-cell tolerance, and immune deviation. J Allergy Clin Immunol 2007; 120(3): 707-713.

97 Yoshitomi T, Nakagami Y, Hirahara K et al. Intraoral administration of a T-cell epitope peptide induces immunological tolerance in Cry j 2-sensitized mice. J Pept Sci 2007; 13(8): 499-503.
98 Chen Q, Xia J, Lin M et al. Serum interleukin-6 in patients with burning mouth syndrome and relationship with depression and perceived pain. Mediators Inflamm 2007; 2007 45327.

(c) (i) $(-)$ This work is licensed under a Creative Commons Attribution-

NonCommercial-NoDerivs 3.0 Unported License. The images or other thir party material in this article are included in the article's Creative Commons license, unless indicated otherwise in the credit line; if the material is not included under the Creative

Commons license, users will need to obtain permission from the license holder to reproduce the material. To view a copy of this license, visit http://creativecommons.org/licenses/

by-nc-nd/3.0/ 